\title{
Anchoring of Aminophosphonates on Titanium Oxide for Biomolecular Coupling
}

Published as part of The Journal of Physical Chemistry virtual special issue "Hai-Lung Dai Festschrift".

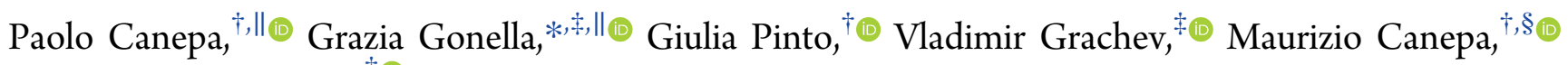
and Ornella Cavalleri* ${ }^{\dagger}+$ (i)

${ }^{\dagger}$ OPTMATLAB, Department of Physics, University of Genova, via Dodecaneso 33, 16146 Genova, Italy

${ }^{\ddagger}$ Max Planck Institute for Polymer Research, Ackermannweg 10, 55128 Mainz, Germany

${ }^{\S}$ INFN, Sezione di Genova, Via Dodecaneso 33, 16146 Genova, Italy

Supporting Information

ABSTRACT: Aminophosphonates were chosen for a first step functionalization of $\mathrm{TiO}_{2}$ grown on titanium, as they possess a phosphonate group on one end, that can be exploited for coupling with the oxide surface, and an amino group on the other end to enable further functionalization of the surface. The deposition of aminophosphonates with different chain lengths (6 and 12 methylenes) was investigated. Oxygen plasma treatment proved useful in increasing the number of $-\mathrm{OH}$ groups at the $\mathrm{TiO}_{2}$ surface, thus helping to anchor the aminophosphonates. By combining different surface-sensitive experimental techniques, we found the existence of a discontinuous monolayer where the molecules are covalently coupled to the $\mathrm{TiO}_{2}$ surface. For the molecules with longer chains, we find evidence of their covalent coupling to the surface through $\mathrm{Ti}-\mathrm{O}-\mathrm{P}$ bond formation, of the exposure of the amino groups at the outer surface, and of an increase in the order of the layer upon thermal annealing.

\section{INTRODUCTION}

Biomaterials are needed for the fabrication of medical devices where they are in direct contact with biological systems. ${ }^{1}$ Among all of the materials (metals, polymers, ceramics) ${ }^{2}$ suitable to interact with body fluids, metals are largely used for orthopedic and dental implants thanks to their inertness and structural/mechanical properties. ${ }^{3}$ In the last decades, titanium and its alloys have been widely exploited for implants. This is due to their low Young's moduli which ensure a good mechanical coupling with the bone tissue and their resistance to corrosion in body fluids. ${ }^{4}$ A layer of native oxide readily forms on the surface of titanium, and while the bulk properties of the material are important for an effective mechanical coupling of the implant, its surface properties play a crucial role for the fate of the implant, since the surface is directly involved in the interaction between the material and the surrounding tissues. Complex biochemical reactions happen at the surface and are mainly due to the fact that the human body may recognize such surfaces as foreign. The human body thus reacts by encasing the foreign object in granulation/fibrotic tissues that will eventually lead to implant failure. ${ }^{5}$ Together with biocompatibility and osseointegration, another soughtafter requirement for the surface is to possess antimicrobial properties. In fact, one of the major causes of failure for implants is related to the risk of infections. ${ }^{6-8}$

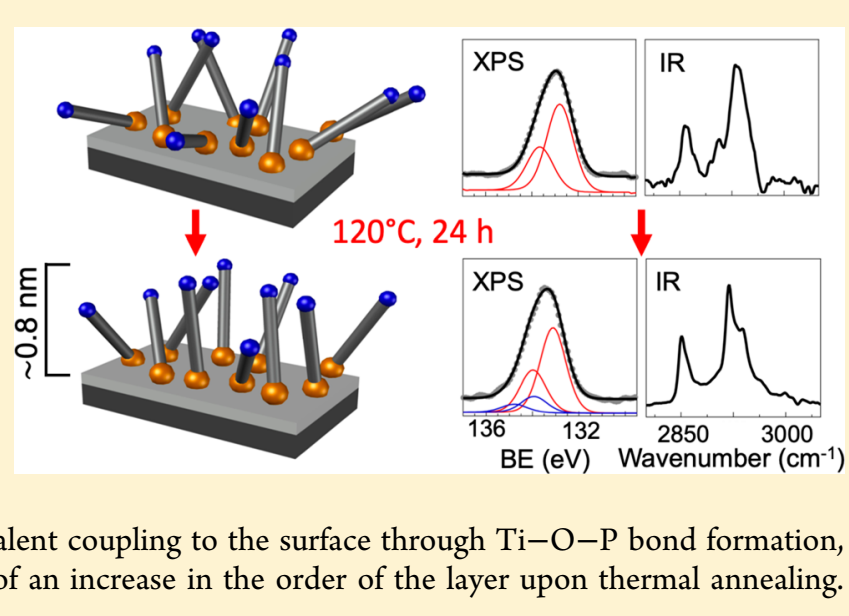

The colonization of the material surface by bacteria from air, blood, or tissues around the wound can be divided into two steps: an initial reversible interaction between the implant surface and the bacterial membrane, followed by a second irreversible stage of binding strengthening in which bacteria form a stable biofilm. ${ }^{9}$ Surface properties like roughness, charge, stiffness, hydrophobicity, hydrogen bonding capacity, and van der Waals forces affect the first stage of bacterial adhesion. ${ }^{10,11}$ Since microorganism colonization depends on many factors, different approaches can be devised to prevent or eradicate bacterial adhesion.

One strategy to confer antibacterial properties to the implant surface employs the functionalization of the surfaces with proper organic or biological molecules. Different classes of molecules have been investigated from quaternary ammonium compounds, ${ }^{12}$ to phosphonium salts, ${ }^{13}$ guanidine polymers, ${ }^{14}$ or polycations. ${ }^{12}$ Polymeric coatings tuned to allow an overtime release of biocide compounds like antibiotics, ${ }^{15,16}$ silver ions, or nanoparticles ${ }^{17-19}$ have been tested as well. Promising molecules to be exploited to endow $\mathrm{TiO}_{2}$ surfaces with antibacterial properties are antimicrobial peptides

Received: April 30, 2019

Revised: June 14, 2019

Published: June 14, 2019 
(AMPs). ${ }^{20}$ Covalent coupling of AMPs to the oxide surface through the use of spacer molecules has the advantage of a robust anchoring and a good accessibility/availability of the active molecule. Different anchoring groups can be exploited to bind the spacer molecules to the oxide surface: chlorosilanes, ${ }^{21}$ hydroxamic acid, ${ }^{22}$ carboxylic acids, ${ }^{23}$ or phosphoric and phosphonic acids. ${ }^{24-26}$ Each family of molecules presents a particular behavior: silanes have the tendency to form multilayers with no controllable polymerization, and carboxylic acids have quite unstable binding with the surface (especially compared to phosphonates $\left.{ }^{27,28}\right)$. On the other hand, alkyl phosphates and phosphonates have been shown to form more stable and well-defined monolayers on oxide surfaces. In particular, compared to silane SAMs, phosphonate monolayers present higher hydrolytic stability in physiological ambient and do not require surface acid treatment to obtain high coverage $^{29,30}$ which is especially important for medical device coatings. In particular, a phosphonic acid anchor group shows great potential for aluminum and other metals. ${ }^{31,32}$ Because of their characteristics, phosphonates with different alkyl chains have been chosen, in the present work, for the surface functionalization of $\mathrm{TiO}_{2}$ with the final goal to prepare surfaces that will provide amino groups available for further covalent coupling with AMPs.

While the work is mainly focused on the functionalization for biomedical applications, the fact that $\mathrm{TiO}_{2}$ is widely used in paints, ${ }^{33}$ food, ${ }^{34}$ cosmetics, ${ }^{35}$ plastics, ${ }^{36}$ photocatalysis, ${ }^{37}$ sensors, $^{38}$ and solar cells ${ }^{39,40}$ makes its functionalization of broader interest.

\section{MATERIALS AND METHODS}

Materials. Titanium foil $99.6+\%$ purity (purchased from Advent Research Materials Ltd.) was used as substrate.

6-Aminohexylphosphonic acid hydrochloride salt $\left(\left(\mathrm{NH}_{2}\right)-\right.$ $\left(\mathrm{CH}_{2}\right)_{6}-\mathrm{PO}(\mathrm{OH})_{2} \mathrm{HCl}, 95 \%$ pure, hereafter referred to as AC6P) (Scheme 1a) and 12-aminododecylphosphonic acid

Scheme 1. Structural Formulas of (a) AC6P and (b) AC12P (a)<smiles>NCCCCCP(=O)(O)O</smiles>

(b)<smiles>NCCCCCCCCCCP(=O)(O)O</smiles>

hydrochloride salt $\left(\left(\mathrm{NH}_{2}\right)-\left(\mathrm{CH}_{2}\right)_{12}-\mathrm{PO}(\mathrm{OH})_{2} \mathrm{HCl}, 95 \%\right.$ pure, hereafter referred to as $\mathrm{AC12P}$ ) (Scheme 1b) were purchased from SiKÉMIA (France) and used without further purification.

Absolute ethanol (99.8\%, Sigma-Aldrich) and acetone (analytical grade, Fisher Chemicals) were used as received. Milli-Q water form Millipore (resistivity $\geq 18 \mathrm{M} \Omega \cdot \mathrm{cm}$ ) was used.

Substrate Preparation. Ti foil was cut in $1 \mathrm{~cm} \times 1 \mathrm{~cm}$ squares. The samples were polished using a polishing machine (Struers Labopol-5) with a grinding plane rotating at 200-400 rpm and SiC paper with P1000, P2500, and P4000 grain size (Fepa-P scale). All samples were ultrasonically rinsed sequentially for $5 \mathrm{~min}$ in Milli-Q water, $5 \mathrm{~min}$ in ethanol, and $20 \mathrm{~min}$ in acetone and finally rinsed again in Milli-Q water. The samples were dried in a $\mathrm{N}_{2}$ flow. Ti readily oxidizes when exposed to air; therefore, a native oxide layer forms on the polished samples. Before molecular deposition, samples were treated in an oxygen plasma chamber for $15 \mathrm{~min}$ at a power of $100 \mathrm{~W}$ and subsequently quenched in Milli-Q water.
Aminophosphonate Deposition. Molecular deposition on $\mathrm{TiO}_{2}$ was carried out in $0.2 \mathrm{mg} / \mathrm{mL}$ solutions at $60{ }^{\circ} \mathrm{C}$ for $24 \mathrm{~h}$. AC6P was dissolved in Milli-Q water, while AC12P was dissolved in absolute ethanol due to its poor solubility in water. After molecular deposition, the samples were either rinsed in the corresponding solvent, dried with a stream of nitrogen and analyzed, or postannealed at $120{ }^{\circ} \mathrm{C}$ for $24 \mathrm{~h}$ in a $\mathrm{N}_{2}$ atmosphere. After heat treatment, the samples were rinsed and dried as described above.

Atomic Force Microscopy (AFM). The sample morphology was analyzed with a Multimode/Nanoscope V system (Bruker). Tapping mode AFM measurements were performed using $\mathrm{Si}$ cantilevers (OMCL-AC160TS, Olympus) with a typical resonant frequency of $\sim 300 \mathrm{kHz}$ and a nominal tip radius of $\sim 7 \mathrm{~nm}$. Data were analyzed with Nanoscope v7.30.

To evaluate the thickness of the aminophosphonate layers, nanoshaving experiments were performed by locally applying an increased AFM tip load in order to selectively remove deposited molecules. ${ }^{4-43}$ Shaving experiments were performed in contact mode using a $\mathrm{Si}_{3} \mathrm{~N}_{4}$ cantilever (OMCLTR800PSA, Olympus) with an elastic constant of $0.58 \mathrm{~N} \mathrm{~m}^{-1}$. Typical forces applied for shaving were of about $100 \mathrm{nN}$, while forces of about $0.1-0.3 \mathrm{nN}$ were used for imaging.

X-ray Photoelectron Spectroscopy (XPS). The chemical analysis of the sample surfaces was carried out by high resolution XPS measurements using a PHI 5600 MultiTechnique apparatus. An X-ray Al-monochromatized source $(h \nu=1486.6 \mathrm{eV})$ was used. Survey spectra were acquired using a pass-energy of $187.85 \mathrm{eV}$, while high resolution spectra were acquired with a pass-energy of $23.5 \mathrm{eV}$. The binding energy scale was calibrated by setting the $\mathrm{C} 1 \mathrm{~s}$ of adventitious carbon at $284.8 \mathrm{eV}$. XPS spectra were analyzed with Igor software (Wavemetrics). Where not differently indicated, a Voigt function (30\% Gaussian) was used for deconvolution. The asymmetric metallic behavior was modeled using the Doniach-Sunjic model. ${ }^{44}$ The background due to inelastically scattered photoelectrons, calculated using the model proposed by Shirley, ${ }^{45}$ was subtracted from raw data. Spin-orbit splitting values used for deconvolution were as follows: Ti $2 \mathrm{p}, 5.70 \mathrm{eV}$; P 2p, $0.86 \mathrm{eV}$.

Infrared Spectroscopy (IR). IR spectra in a grazing angle reflectance geometry (GI-FTIR), with an incidence angle of (9 $\pm 1)^{\circ}$ with respect to the substrate, were acquired using a Bruker Vertex 70 FTIR spectrometer in absorbance mode using p-polarized light. The sample compartment was purged with dry air to reduce the contribution from $\mathrm{CO}_{2}$ and $\mathrm{H}_{2} \mathrm{O}$ absorption bands. Spectra at three different points for each sample were collected to test homogeneity.

\section{RESULTS AND DISCUSSION}

Monolayer Formation. The plasma treatment promotes oxide growth, helps in removing adventitious species, and enriches the surface with $-\mathrm{OH}$ groups, as shown by the XPS analysis reported in the Supporting Information (see section $\mathrm{S} 1$ and Figure S1) and is thus used before the functionalization of the substrate with aminophosphonates.

As shown by typical AFM images of the oxidized $\mathrm{Ti}$ substrate before (Figure 1a, top) and after (Figure 1a, bottom) exposure to $\mathrm{AC} 12 \mathrm{P}$, molecular deposition results in the formation of molecular islands randomly distributed on the surface with a height in the range 0.6-1.0 nm. Further information on the film thickness has been obtained by nanoshaving experiments. 

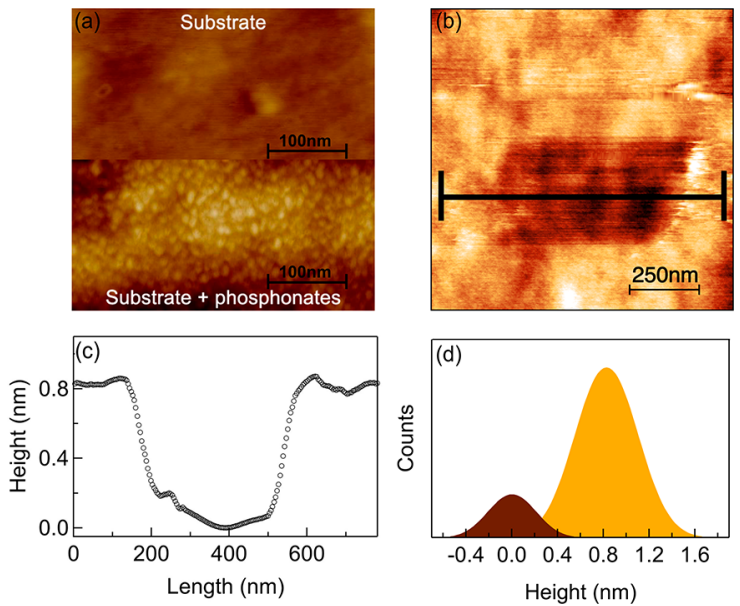

Figure 1. (a) AFM image of polished $\mathrm{Ti}$ (top) before and (bottom) after AC12P deposition $(z$-scale $=5 \mathrm{~nm})$. (b) AFM image of AC12P nanoshaving, (c) height profile along the black line in (b), (d) height distribution of the AFM image in (b).
The AFM image in Figure $1 \mathrm{~b}$ shows a darker area in the center where molecules have been removed under high load tip scans at $100-150 \mathrm{nN}$. The resulting naked substrate surface is surrounded by the AC12P layer. After shaving, in order to minimize the perturbation of the film by the AFM tip and get reliable height estimates, imaging was performed at very low applied force $(0.1-0.2 \mathrm{nN})$.

The $z$-profile in Figure 1c along the black line in Figure $1 \mathrm{~b}$ allows for an immediate evaluation of the AC12P layer thickness. However, for a statistically significant evaluation of the layer thickness, the height histogram of the image in Figure $1 \mathrm{~b}$ can be analyzed and is shown in Figure $1 \mathrm{~d}$. The histogram is characterized by two peaks. The oxide surface and the film correspond to the bell-shaped peaks centered at $0 \mathrm{~nm}$ and at $\sim 0.8 \mathrm{~nm}$, respectively. The distance between the two peaks, fitted by Gaussian profiles, provides the thickness of the AC12P film. A statistical analysis of different patches on several samples provided an average value of the film thickness of 0.8 $\pm 0.3 \mathrm{~nm}$.
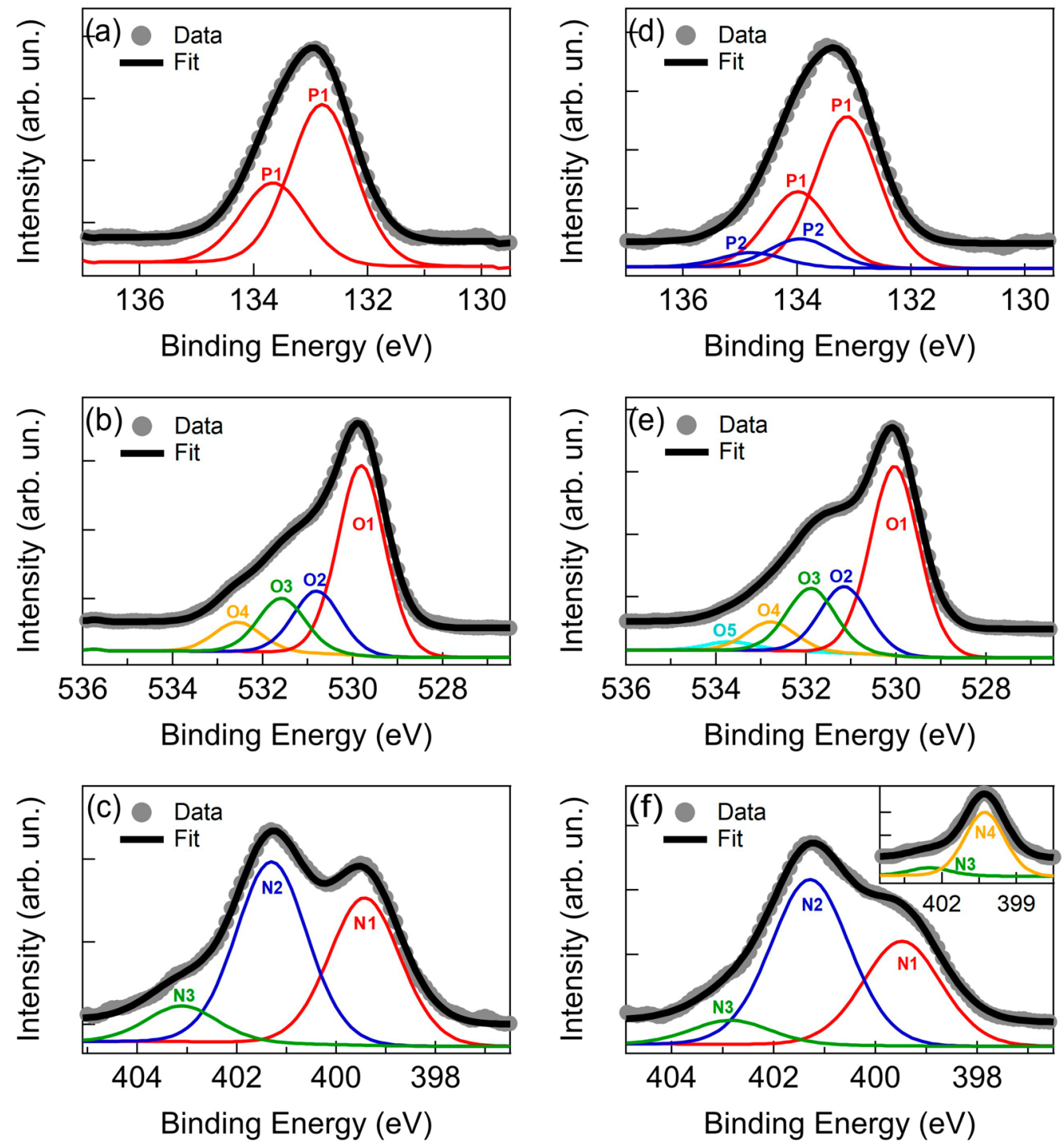

Figure 2. XPS spectra of AC12P monolayers before (a) P 2p, (b) O 1s, and (c) N 1s and after annealing (d) P 2p, (e) O 1s, and (f) N 1s. The fitted components are shifted downward for clarity. 
This order of magnitude of the film thickness has been confirmed by spectroscopic ellipsometry measurements (see the Supporting Information, section SII). The variation of the ellipsometric variables $\Delta$ and $\Psi$ after the AC12P deposition is fully compatible with the formation of a single layer with a refractive index typical of organic molecular films. ${ }^{46-49}$

Similar analysis was performed on AC6P films (see the Supporting Information, section SIII). AFM imaging (see the Supporting Information, section SIII) shows that molecular deposition results in a surface morphology change with the formation of irregular islands absent on the bare substrate. The images are however less defined compared to those of AC12P films. Similarly, SE spectra acquired after AC6P deposition are slightly shifted with respect to those of the bare substrate; however, the shift is too small to allow for a reliable quantitative evaluation of the film thickness. Therefore, we can only conclude that both AFM and SE qualitatively confirm AC6P deposition.

Anchoring. The surface chemical composition of AC6P and AC12P films has been investigated by XPS. Analysis of the Ti $2 p$ spectra acquired after deposition of AC6P and AC12P did not show any appreciable change with respect to the Ti $2 p$ spectra of bare substrates (see the Supporting Information, section SI). Molecular relevant XPS core level regions are reported in Figure 2, which shows the $\mathrm{P} 2 \mathrm{p}, \mathrm{O} 1 \mathrm{~s}$, and $\mathrm{N}$ 1s spectra of the AC12P before $(a-c)$ and after $(d-f)$ annealing. Similar spectra were obtained for AC6P films (see the Supporting Information, section SIII). The P $2 \mathrm{p}$ core level region (Figure 2a) presents a doublet, P1 (each component with $\mathrm{fwhm}=1.4 \mathrm{eV}$ ), with the main $2 \mathrm{p} 3 / 2$ component at $132.8 \pm 0.2 \mathrm{eV}$. In comparison with the position of the P $2 \mathrm{p}$ component observed in the powder (see the Supporting Information, section SIV, Figure S4a), a slight shift can be observed confirming that the aminophosphonate binding state has changed (from unbound to bound). The assignment of this component is nevertheless complicated by the proximity of the binding energies of the single $\left(\mathrm{PO}_{2}(\mathrm{OH})^{-}\right)$and double $\left(\mathrm{PO}_{3}{ }^{2-}\right)$ coordination predicted in some works. ${ }^{50,51}$

The $\mathrm{O} 1 \mathrm{~s}$ region reported in Figure $2 \mathrm{~b}$ can be deconvoluted with four Voigt functions with fwhm $=1.2 \mathrm{eV}$ each. The signal of the $\mathrm{TiO}_{2}$ substrate, $\mathrm{O} 1$, is clearly visible at a binding energy of $529.8 \pm 0.2 \mathrm{eV}^{52,53}$ Binding of the phosphonate to the substrate is confirmed by the $\mathrm{O} 2$ component at $530.8 \pm 0.2 \mathrm{eV}$ which can be assigned to the Ti-O-P. ${ }^{26,28,54-56}$ The O3 component at $531.6 \pm 0.2 \mathrm{eV}$ has been attributed to some $\mathrm{P}-$ $\mathrm{OH}$ that has not been covalently bound to the surface but is nevertheless coordinated to the hydroxyl groups present on the substrate surface. ${ }^{57}$ The fourth component $\mathrm{O} 4$ at $532.6 \pm 0.2$ $\mathrm{eV}$ is mainly due to the unbound $\mathrm{P}=\mathrm{O}$ of the phosphonates $^{53,58}$ and some adventitious $-\mathrm{COO}^{-52,59}$ The $\mathrm{Ti}-\mathrm{O}-\mathrm{P}$ bridge between the molecules and the substrate is derived from the interaction between the $\mathrm{P}-\mathrm{OH}$ groups of the amino-phosphonates with the $-\mathrm{OH}$ groups of the plasma treated substrate through the condensation of water. Considering the energy position of the $\mathrm{P}-\mathrm{OH}$ group obtained from the aminophosphonate powder $(\mathrm{O} 2$ at $531.2 \pm 0.2 \mathrm{eV}$; see the Supporting Information, section SIV, Figure S4b), a small shift to lower energy is observed, partially in agreement with the literature reporting a shift of $\sim 1 \mathrm{eV}$ for any proton removed from the phosphonate head upon adsorption. ${ }^{53}$

The $\mathrm{N}$ 1s spectrum reported in Figure $2 \mathrm{c}$ presents three components $(\mathrm{fwhm}=1.7 \mathrm{eV})$. The two peaks, N1 and N2, at binding energies of $399.4 \pm 0.2$ and $401.3 \pm 0.2 \mathrm{eV}$ can be assigned to amine nitrogen $\left(-\mathrm{NH}_{2}\right)$ and protonated amine nitrogen $\left(-\mathrm{NH}_{3}{ }^{+}\right),{ }^{59-61}$ respectively. The third peak, N3, at $403.1 \pm 0.2 \mathrm{eV}$ was already observed on plasma treated substrates (see the Supporting Information, section SI, Figure S1f) and can be assigned to adventitious nitrogen that has interacted with oxygen of the oxide layer. The presence, in the deposited film, of the $\mathrm{NH}_{2}$ signal, together with the $\mathrm{NH}_{3}{ }^{+}$ signal observed on the AC12P powder (see Supporting Information, section SIV, Figure S4c), can be explained by the electrostatic repulsion between charged $\mathrm{NH}_{3}{ }^{+}$groups. Due to electrostatic repulsion, a fraction of protonated amino groups deprotonates as already reported for SAMs functionalized with ionizable groups (i.e., $-\mathrm{COOH}){ }^{62}$

Covalent phosphonate binding with a $\mathrm{TiO}_{2}$ substrate is expected to be strengthened with a post deposition annealing. ${ }^{63,64}$ This reinforcement is due to a larger number of oxygen bridges between the phosphorus of the aminophosphonates and the substrate. This effect can be investigated by analyzing the $\mathrm{P} 2 \mathrm{p}$ and $\mathrm{O}$ 1s core level regions.

The P $2 \mathrm{p}$ core level region of annealed samples is reported in Figure 2d; after annealing, two doublets are necessary for the signal deconvolution. The more intense doublet, $\mathrm{P} 1$, with the main $2 \mathrm{p} 3 / 2$ component at $133.2 \pm 0.2 \mathrm{eV}$ is still related to the presence of monodentate $\left(\mathrm{PO}_{2}(\mathrm{OH})^{-}\right)$and bidentate $\left(\mathrm{PO}_{3}{ }^{2-}\right)$ coordination. The second doublet, $\mathrm{P} 2$, with the main $2 \mathrm{p} 3 / 2$ component at $134.0 \pm 0.2 \mathrm{eV}$ can be assigned to the tridentate coordination between the aminophosphonate and the substrate. This new type of coordination is also the key to interpreting the shifts of all of the P-associated components in the $\mathrm{O} 1 \mathrm{~s}$ spectrum.

Figure 2e reports the high resolution XPS spectrum of the $\mathrm{O}$ 1 s core level region of an annealed $\left(120{ }^{\circ} \mathrm{C}\right.$ for $24 \mathrm{~h}$ in nitrogen) sample, showing a noticeable shoulder at a binding energy higher than the $\mathrm{TiO}_{2}$ component $(\mathrm{O}$ 1s at $530.0 \pm 0.2$ $\mathrm{eV}$ ), especially in comparison with the preannealing spectrum in Figure $2 \mathrm{~b}$. The $\mathrm{O} 2$ and $\mathrm{O} 3$ components, related to $\mathrm{Ti}-\mathrm{O}-$ $\mathrm{P}$ and the $\mathrm{P}-\mathrm{OH}-\mathrm{Ti}$, respectively, have grown in intensity, and also, their binding energies slightly increased, $531.2 \pm 0.2$ and $531.9 \pm 0.2 \mathrm{eV}$, respectively. The $\mathrm{O} 4$ component at 532.8 $\pm 0.2 \mathrm{eV}$ is mainly due to the presence of $-\mathrm{COO}^{-}$and some residual $\mathrm{P}=\mathrm{O}$ (as before annealing). The presence of a new component, O5, at higher energy $(533.7 \pm 0.2 \mathrm{eV})$ represents adventitious $-\mathrm{COOH}$.

The nitrogen spectrum reported in Figure $2 \mathrm{f}$ presents again three components at binding energies which agree, within the experimental uncertainties, with those observed before annealing. Their fwhm $(1.8 \mathrm{eV})$ is slightly larger compared to the fwhm before annealing. The $\mathrm{NH}_{2} / \mathrm{NH}_{3}{ }^{+}$ratio showed small variations considering the population of analyzed samples. This variation is probably associated with a slight difference in the surface organization of the molecules, that influences the interaction between the amine groups. It is interesting to note that annealing experiments performed in a noncontrolled atmosphere (i.e., in air) showed a different shape of the nitrogen peak (inset of Figure $2 \mathrm{f}$ ). In this case, the $\mathrm{N}$ 1s signal was deconvoluted with two peaks, a main one, N4, at a binding energy of $400.3 \pm 0.2 \mathrm{eV}$ and a weak one, $\mathrm{N} 3$, at $403.2 \pm 0.2 \mathrm{eV}$, already present before annealing. A very similar $\mathrm{N}$ 1s signal was observed on aminophosphonate films aged in ambient at room temperature for 12 months. The N4 component can be assigned to formation of $-\mathrm{N}=\mathrm{C}=\mathrm{O},{ }^{65,66}$ resulting from amine groups of the aminophosphonates that underwent a reaction with $\mathrm{CO}_{2}$. This observation further 
Table 1. Binding Energies of the Spectral Components Used to Deconvolve the XPS Spectra

\begin{tabular}{|c|c|c|c|c|c|c|c|c|c|c|}
\hline & \multicolumn{5}{|c|}{ O 1s } & \multicolumn{2}{|c|}{ P $2 p$} & \multicolumn{3}{|c|}{$\mathrm{N} 1 \mathrm{~s}$} \\
\hline & $\mathrm{O}_{1}$ & $\mathrm{O}_{2}$ & $\mathrm{O}_{3}$ & $\mathrm{O}_{4}$ & $\mathrm{O}_{5}$ & $\mathrm{P}_{1}$ & $\mathrm{P}_{2}$ & $\mathrm{~N}_{1}$ & $\mathrm{~N}_{2}$ & $\mathrm{~N}_{3}$ \\
\hline powder & & & 531.2 & 532.7 & & 133.2 & & & 401.4 & \\
\hline deposition & 529.8 & 530.8 & 531.6 & 532.6 & & 132.8 & & 399.4 & 401.3 & 403.1 \\
\hline annealing in $\mathrm{N}_{2}$ & 530.0 & 531.2 & 531.9 & 532.8 & 533.7 & 133.2 & 134.0 & 399.6 & 401.4 & 403.2 \\
\hline
\end{tabular}
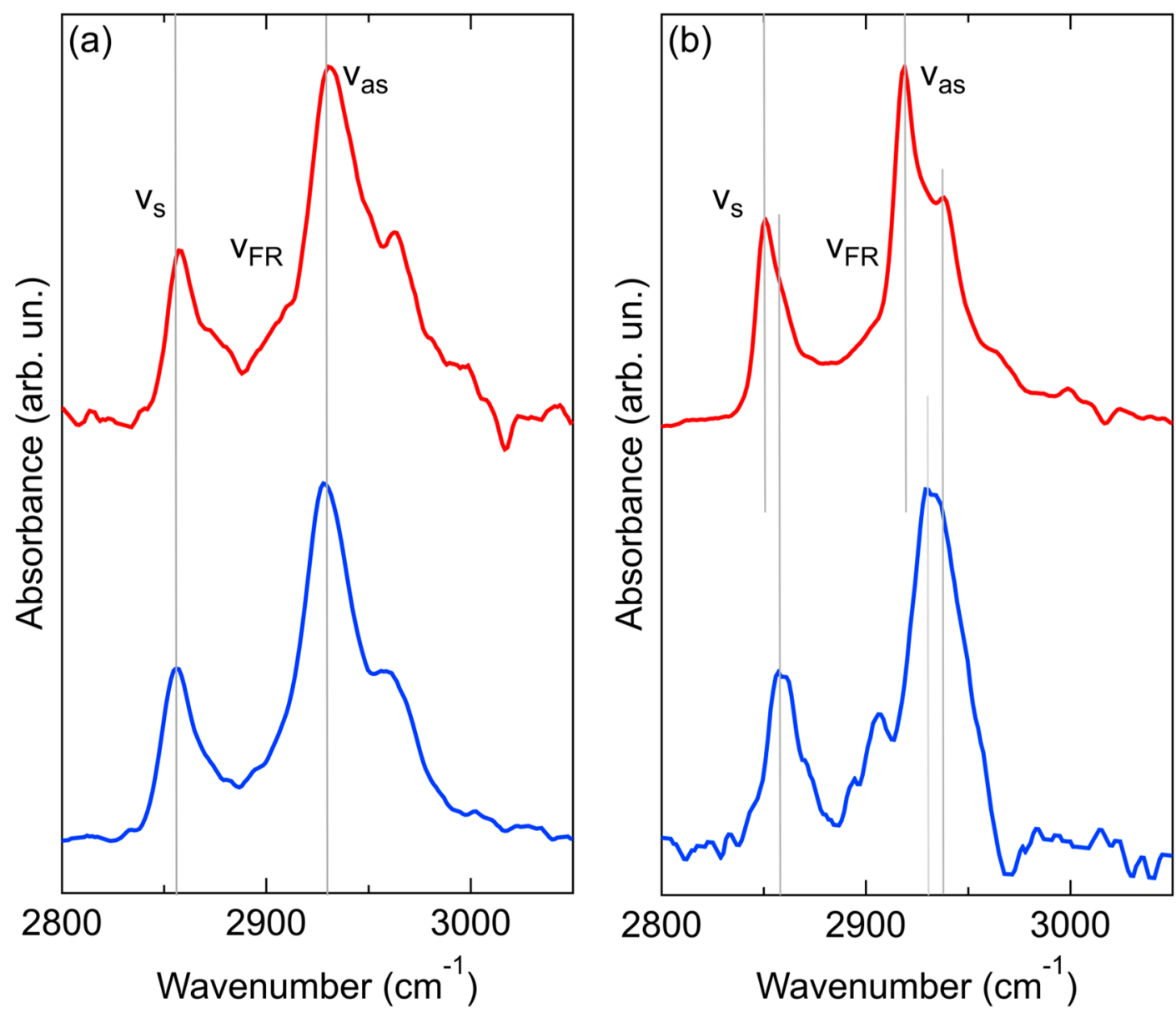

Figure 3. GIR-FTIR spectra of (a) AC6P and (b) AC12P monolayers on $\mathrm{TiO}_{2}$ in the $\mathrm{CH}$ stretching region for (blue curves) nonannealed and (red curves) annealed samples. The spectra are offset for clarity.

supports anchoring of the aminophosphonates to $\mathrm{TiO}_{2}$ through the phosphonate group while leaving the amino groups free to react. In fact, aminophosphonates could, in principle, also bind to $\mathrm{TiO}_{2}$ through the amino group even though this is energetically unfavorable. ${ }^{67}$ The formation of $\mathrm{N}=\mathrm{C}=\mathrm{O}$ upon annealing in air indicates that attention should be paid to perform annealing in an inert atmosphere in order to preserve unreacted amino groups, available for further coupling.

Table 1 sums up the binding energy positions of the spectral components used in this work to deconvolute the XPS spectra.

Monolayer Ordering. In order to address the order of the formed monolayers, we performed GIR-FTIR in the 2800$3100 \mathrm{~cm}^{-1}$ spectral range, the fingerprint region for $\mathrm{C}-\mathrm{H}$ stretching modes.

Parts $\mathrm{a}$ and $\mathrm{b}$ of Figure 3 show the spectra of AC6P and AC12P on $\mathrm{TiO}_{2}$ (blue) before and (red) after annealing. For the spectra of both samples before annealing (blue), the peak at $\sim 2857 \mathrm{~cm}^{-1}$ is assigned to the $\nu_{\mathrm{s}}\left(\mathrm{CH}_{2}\right)$ mode while that at $\sim 2929 \mathrm{~cm}^{-1}$ to the $\nu_{\text {as }}\left(\mathrm{CH}_{2}\right)$ mode; the latter presents a shoulder on the red side that is assigned to $\nu_{\mathrm{FR}}\left(\mathrm{CH}_{2}\right)$. The position of the $\nu_{\text {as }}\left(\mathrm{CH}_{2}\right)$ peak is closer to that reported for liquid (disordered) alkanes than for crystalline (ordered) ones, ${ }^{68,69}$ indicating that nonannealed AC6P and AC12P monolayers are disordered. For AC6P, the positions and widths of the peaks in Figure $3 \mathrm{a}$ are similar for (blue) nonannealed and (red) annealed monolayers, suggesting that annealing has negligible effects on these films. On the other hand, annealing has clearly a major effect on the AC12P monolayer (Figure $3 \mathrm{~b}$ ), where a new $\nu_{\text {as }}\left(\mathrm{CH}_{2}\right)$ contribution at $\sim 2919 \mathrm{~cm}^{-1}$ is clearly observed in the (red) annealed sample that is narrower than the peak observed at $\sim 2929 \mathrm{~cm}^{-1}$ for the (blue) nonannealed sample. Narrow peaks and lower wavenumbers are characteristic of more ordered monolayers. ${ }^{70} \mathrm{~A}$ shift to lower wavenumbers of the $\nu_{\mathrm{s}}\left(\mathrm{CH}_{2}\right)$ mode $(\sim 2850$ $\left.\mathrm{cm}^{-1}\right)$ is also observed. It is worth pointing out that the $\nu_{\mathrm{s}}$ $\left(\mathrm{CH}_{2}\right)$ mode for AC12P annealed (red curve in Figure $3 \mathrm{~b}$ ) is still quite broad and could be the sum of two contributions. The spectrum can then be explained by the presence of two populations of molecules, where the new population, at lower 
wavenumbers, is more ordered and is produced through annealing.

\section{CONCLUSIONS}

We investigated the self-assembly of aminophosphonates on plasma treated polished $\mathrm{Ti}$ surfaces as a first step toward the surface immobilization of antimicrobial peptides. Oxygen plasma treatment was exploited to increase the thickness of the substrate native oxide layer and to enrich its surface in $-\mathrm{OH}$ groups, useful for organophosphonate anchoring. Two aminophosphonates with different lengths of the alkyl chain, AC6P and AC12P, were used. In both cases, a discontinuous monolayer was formed on the $\mathrm{TiO}_{2}$ surface, even though longer chain molecules resulted in more ordered layers, especially after thermal annealing.

For AC12P, the combination of AFM imaging and shaving with SE analysis indicates a layer thickness of $\sim 0.8 \mathrm{~nm}$, in agreement with a single molecular layer.

XPS analysis indicates for both AC6P and AC12P layers the presence of the expected atomic signals. The deconvolution of the $\mathrm{P} 2 \mathrm{p}$ and $\mathrm{O} 1 \mathrm{~s}$ signals indicates the formation of $\mathrm{P}-\mathrm{O}-\mathrm{Ti}$ bonds in agreement with mono- and bidentate phosphonate binding modes. The evolution of the $\mathrm{P} 2 \mathrm{p}$ signal upon thermal annealing agrees with the formation of some tridentate bonds. IR analysis indicates that in the case of $\mathrm{AC} 12 \mathrm{P}$ thermal annealing also influences the molecular packing, improving the order of the alkyl chains. Further annealing experiments performed in air indicate that amino groups can react with oxygen species. To preserve unreacted amino groups to be exploited for further functionalization, annealing therefore has to be performed in an inert atmosphere. Indeed, preliminary experiments successfully exploited unreacted amino groups to anchor single amino acids to AC12P. Future experiments will focus on the covalent coupling of AMP to confer antimicrobial properties to the $\mathrm{TiO}_{2}$ surface.

\section{ASSOCIATED CONTENT}

\section{S Supporting Information}

The Supporting Information is available free of charge on the ACS Publications website at DOI: 10.1021/acs.jpcc.9b04077.

Information regarding the chemical characterization of the substrate, AC6P films, and aminophosphonate powders by XPS and the SE data of AC12P film (PDF)

\section{AUTHOR INFORMATION}

\section{Corresponding Authors}

*E-mail: gonella@mpip-mainz.mpg.de.

*E-mail: cavalleri@fisica.unige.it.

\section{ORCID}

Paolo Canepa: 0000-0002-2205-286X

Grazia Gonella: 0000-0002-0470-4043

Giulia Pinto: 0000-0001-7007-6287

Vladimir Grachev: 0000-0002-7239-5887

Maurizio Canepa: 0000-0002-5148-1233

Ornella Cavalleri: 0000-0002-3473-2424

\section{Author Contributions}

"P.C., G.G.: Equal contribution.

\section{Notes}

The authors declare no competing financial interest.

\section{ACKNOWLEDGMENTS}

The authors thank Flavio Gatti and Michele Biasotti for assistance in substrate preparation and Francesco Bisio and Michele Magnozzi for helpful discussion on SE data analysis. G.G. thanks Walter Scholdei for support in the IR measurements and Maksim Grechko for helpful discussion. This work has been performed under the project DIFILAB of the Università degli Studi di Genova. It has been supported by the Ministero dell'Istruzione, dell'Università e della Ricerca (grant RBAP11ETKA-005), and by funding from the Università degli Studi di Genova (FRA2015). P.C. and M.C. are not relatives.

\section{REFERENCES}

(1) Williams, D. F. On the Nature of Biomaterials. Biomaterials 2009, 30, 5897-5909.

(2) Mihov, D.; Katerska, B. Some Biocompatible Materials Used in Medical Practice. Trakia J. Sci. 2010, 8, 119-125.

(3) Mahapatro, A. Bio-Functional Nano-Coatings on Metallic Biomaterials. Mater. Sci. Eng., C 2015, 55, 227-251.

(4) Williams, D. F. Biomaterials 2008, 29, 2941-2953.

(5) Biomaterials Surface Science; Taubert, A., Mano, J. F., RodrìguezCabello, J. C., Eds.; Wiley-VCH: Weinheim, Germany, 2013.

(6) Hetrick, E. M.; Schoenfisch, M. H. Reducing Implant-Related Infections: Active Release Strategies. Chem. Soc. Rev. 2006, 35, 780789.

(7) Trebse, R.; Pisot, V.; Trampuz, A. Treatment of Infected Retained Implants. J. Bone Joint Surg. Br. 2005, 87-B, 249-256.

(8) Fridkin, S. K.; Jarvis, W. R. Epidemiology of Nosocomial Fungal Infections. Clin. Microbiol. Rev. 1996, 9, 499-511.

(9) Lichter, J. A.; Van Vliet, K. J.; Rubner, M. F. Design of Antibacterial Surfaces and Interfaces: Polyelectrolyte Multilayers as a Multifunctional Platform. Macromolecules 2009, 42, 8573-8586.

(10) Abu-Lail, N. I.; Camesano, T. A. Specific and Nonspecific Interaction Forces between Escherichia Coli and Silicon Nitride, Determined by Poisson Statistical Analysis. Langmuir 2006, 22, 7296-7301.

(11) Park, K. D.; Kim, Y. S.; Han, D. K.; Kim, Y. H.; Lee, E. H. B.; Suh, H.; Choi, K. S. Bacterial Adhesion on PEG Modified Polyurethane Surfaces. Biomaterials 1998, 19, 851-859.

(12) Lewis, K.; Klibanov, A. M. Surpassing Nature: Rational Design of Sterile-Surface Materials. Trends Biotechnol. 2005, 23, 343-348.

(13) Kenawy, E. R.; Worley, S. D.; Broughton, R. The Chemistry and Applications of Antimicrobial Polymers: A State-of-the-Art Review. Biomacromolecules 2007, 8, 1359-1384.

(14) Bromberg, L.; Hatton, T. A. Poly(N-Vinylguanidine): Characterization, and Catalytic and Bactericidal Properties. Polymer 2007, 48, 7490-7498.

(15) Aviv, M.; Berdicevsky, I.; Zilberman, M. Gentamicin-loaded bioresorbable films for prevention of bacterial infections associated with orthopedic implants. J.Biomed. Mater. Res. A 2007, 83A, 10-19.

(16) Darouiche, R. O. Antimicrobial Approaches for Preventing Infections Associated with Surgical Implants. Clin. Infect. Dis. 2003, $36,1284-1289$.

(17) Ho, C. H.; Tobis, J.; Sprich, C.; Thomann, R.; Tiller, J. C. Nanoseparated Polymeric Networks with Multiple Antimicrobial Properties. Adv. Mater. 2004, 16, 957-961.

(18) Milović, N. M.; Wang, J.; Lewis, K.; Klibanov, A. M. Immobilized N-Alkylated Polyethylenimine Avidly Kills Bacteria by Rupturing Cell Membranes with No Resistance Developed. Biotechnol. Bioeng. 2005, 90, 715-722.

(19) Stevens, K. N. J.; Crespo-Biel, O.; van den Bosch, E. E. M.; Dias, A. A.; Knetsch, M. L. W.; Aldenhoff, Y. B. J.; van der Veen, F. H.; Maessen, J. G.; Stobberingh, E. E.; Koole, L. H. The Relationship between the Antimicrobial Effect of Catheter Coatings Containing Silver Nanoparticles and the Coagulation of Contacting Blood. Biomaterials 2009, 30, 3682-3690. 
(20) Shukla, A.; Fleming, K. E.; Chuang, H. F.; Chau, T. M.; Loose, C. R.; Stephanopoulos, G. N.; Hammond, P. T. Controlling the Release of Peptide Antimicrobial Agents from Surfaces. Biomaterials 2010, 31, 2348-2357.

(21) Ulman, A. Formation and Structure of Self-Assembled Monolayers. Chem. Rev. 1996, 96, 1533-1554.

(22) Folkers, J. P.; Gorman, C. B.; Laibinis, P. E.; Buchholz, S.; Whitesides, G. M.; Nuzzo, R. G. Self-Assembled Monolayers of LongChain Hydroxamic Acids on the Native Oxide of Metals. Langmuir 1995, 11, 813-824.

(23) Aronoff, Y. G.; Chen, B.; Lu, G.; Seto, C.; Schwartz, J.; Bernasek, S. L. Stabilization of Self-Assembled Monolayers of Carboxylic Acids on Native Oxides of Metals. J. Am. Chem. Soc. 1997, 119, 259-262.

(24) Pujari, S. P.; Scheres, L.; Marcelis, A. T. M.; Zuilhof, H. Covalent Surface Modification of Oxide Surfaces. Angew. Chemie 2014, 53, 6322-6356.

(25) Brovelli, D.; Häehner, G.; Ruiz, L.; Hofer, R.; Kraus, G.; Waldner, A.; Schlösser, J.; Oroszlan, P.; Ehrat, M.; Spencer, N. D.; et al. Highly Oriented, Self-Assembled Alkanephosphate Monolayers on Tantalum (V) Oxide Surfaces. Langmuir 1999, 15, 4324-4327.

(26) Textor, M.; Ruiz, L.; Hofer, R.; Rossi, A.; Feldman, K.; Häehner, G.; Spencer, N. D. Structural Chemistry of Self-Assembled Monolayers of Octadecylphosphoric Acid on Tantalum Oxide Surfaces. Langmuir 2000, 16, 3257-3271.

(27) Thissen, P.; Valtiner, M.; Grundmeier, G. Stability of Phosphonic Acid Self-Assembled Monolayers on Amorphous and Single-Crystalline Aluminum Oxide Surfaces in Aqueous Solution. Langmuir 2010, 26, 156-164.

(28) Adolphi, B.; Jahne, E.; Busch, G.; Cai, X. Characterization of the Adsorption of omega-(thiophene-3-yl alkyl)Phosphonic Acid on Metal Oxides with AR-XPS. Anal. Bioanal. Chem. 2004, 379, 646652.

(29) Marcinko, S.; Fadeev, A. Y. Hydrolytic Stability of Organic Monolayers Supported on $\mathrm{TiO} 2$ and ZrO2. Langmuir 2004, 20, 2270-2273.

(30) Silverman, B. M.; Wieghaus, K. A.; Schwartz, J. Comparative Properties of Siloxane vs Phosphonate Monolayers on A Key Titanium Alloy. Langmuir 2005, 21, 225-228.

(31) Mutin, P. H.; Guerrero, G.; Vioux, A. Hybrid Materials from Organophosphorus Coupling Molecules. J. Mater. Chem. 2005, 15, $3761-3768$.

(32) Vioux, A.; Le Bideau, J.; Mutin, P. H.; Leclercq, D. In New Aspects in Phosphorus Chemistry IV. Topics in Current Chemistry; Majoral, J. P., Ed.; Springer: Berlin, Heidelberg, 2004; Vol. 232, pp $145-174$.

(33) Karlsson, M. C. F.; Álvarez-Asencio, R.; Bordes, R.; Larsson, A.; Taylor, P.; Steenari, B. M. Characterization of Paint Formulated Using Secondary $\mathrm{TiO} 2$ Pigments Recovered from Waste Paint. J. Coatings Technol. Res. 2019, 16, 607-614.

(34) Yang, Y.; Doudrick, K.; Bi, X.; Hristovski, K.; Herckes, P.; Kaegi, R. Characterization of Food-Grade Titanium Dioxide: The Presence of Nanosized Particles. Environ. Sci. Technol. 2014, 48, 6391-6400.

(35) Weir, A.; Westerhoff, P.; Fabricius, L.; Hristovski, K.; von Goetz, N. Titanium Dioxide Nanoparticles in Food and Personal Care Products. Environ. Sci. Technol. 2012, 46, 2242-2250.

(36) Chaudhari, S.; Shaikh, T.; Pandey, P. A Review on Polymer Tio2 Nanocomposites. Int. J. Eng. Res. Appl. 2013, 3, 1386-1391.

(37) Schneider, J.; Matsuoka, M.; Takeuchi, M.; Zhang, J.; Horiuchi, Y.; Anpo, M.; Bahnemann, D. W. Understanding TiO 2 Photocatalysis: Mechanisms and Materials. Chem. Rev. 2014, 114, 99199986.

(38) Bai, J.; Zhou, B. Titanium Dioxide Nanomaterials for Sensor Applications. Chem. Rev. 2014, 114, 10131-10176.

(39) Bai, Y.; Mora-Seró, I.; De Angelis, F.; Bisquert, J.; Wang, P. Titanium Dioxide Nanomaterials for Photovoltaic Applications. Chem. Rev. 2014, 114, 10095-10130.
(40) Fang, H.; Ma, J.; Wilhelm, M. J.; Rao, Y.; Kuhn, D. L.; Zander, Z.; Delacy, B. G.; Dai, H. Carboxylic Anchoring Dye $p$-Ethyl Red Does Not Adsorb Directly onto $\mathrm{TiO}_{2}$ Particles in Protic Solvents. J. Phys. Chem. C 2019, 123, 8265-8272.

(41) Pinto, G.; Parisse, P.; Solano, I.; Canepa, P.; Canepa, M.; Casalis, L.; Cavalleri, O. Functionalizing Gold with Single Strand DNA: Novel Insight into Optical Properties via Combined Spectroscopic Ellipsometry and Nanolithography Measurements. Soft Matter 2019, 15, 2463-2468.

(42) Solano, I.; Parisse, P.; Gramazio, F.; Cavalleri, O.; Bracco, G.; Castronovo, M.; Casalis, L.; Canepa, M. Spectroscopic Ellipsometry Meets AFM Nanolithography: About Hydration of Bio-Inert oligo(ethylene glycol)-terminated self assembled monolayers on gold. Phys. Chem. Chem. Phys. 2015, 17, 28774-28781.

(43) Seo, K.; Borguet, E.; V, T. U.; Pennsyl, V. Nanolithographic Write, Read, and Erase via Reversible Nanotemplated Nanostructure Electrodeposition on Alkanethiol-Modified $\mathrm{Au}(111)$ in an Aqueous Solution. Langmuir 2006, 22, 1388-1391.

(44) Doniach, S.; Sunjic, M. Many-Electron Singularity in X-Ray Photoemission and X-Ray Line Spectra from Metals. J. Phys. C: Solid State Phys. 1970, 3, 285-291.

(45) Végh, J. The Shirley background revised. J. Electron Spectrosc. Relat. Phenom. 2006, 151, 159-164.

(46) Nuzzo, R. G.; Allara, D. L. Adsorption of Bifunctional Organic Disulfides on Gold Surfaces. J. Am. Chem. Soc. 1983, 105, 4481-4483.

(47) Bain, C. D.; Troughton, E. B.; Tao, Y. T.; Evall, J.; Whitesides, G. M.; Nuzzo, R. G. Formation of Monolayer Films by the Spontaneous Assembly of Organic Thiols from Solution onto Gold. J. Am. Chem. Soc. 1989, 111, 321-335.

(48) Prato, M.; Moroni, R.; Bisio, F.; Rolandi, R.; Mattera, L.; Cavalleri, O.; Canepa, M. Optical Characterization of Thiolate SelfAssembled Monolayers on $\mathrm{Au}(111)$. J. Phys. Chem. C 2008, 112, 3899-3906.

(49) Gonella, G.; Cavalleri, O.; Emilianov, I.; Mattera, L.; Canepa, M.; Rolandi, R. Spectro-Ellipsometry on Cadmium Stearate Langmuir - Blodgett Films. Mater. Sci. Eng., C 2002, 22, 359-366.

(50) Luschtinetz, R.; Frenzel, J.; Milek, T.; Seifert, G. Adsorption of Phosphonic Acid at the TiO 2 Anatase (101) and Rutile (110) Surfaces. J. Phys. Chem. C 2009, 113, 5730-5740.

(51) Ambrosio, F.; Martsinovich, N.; Troisi, A. Effect of the Anchoring Group on Electron Injection: Theoretical Study of Phosphonated Dyes for Dye-Sensitized Solar Cells. J. Phys. Chem. C 2012, 116, 2622-2629.

(52) Tosatti, S.; Michel, R.; Textor, M.; Spencer, N. D. SelfAssembled Monolayers of Dodecyl and Hydroxy-Dodecyl Phosphates on Both Smooth and Rough Titanium and Titanium Oxide Surfaces. Langmuir 2002, 18, 3537-3548.

(53) Wagstaffe, M.; Thomas, A. G.; Jackman, M. J.; Torres-Molina, M.; Syres, K. L.; Handrup, K. An Experimental Investigation of the Adsorption of a Phosphonic Acid on the Anatase $\mathrm{TiO}_{2}(101)$ Surface. J. Phys. Chem. C 2016, 120, 1693-1700.

(54) Bozzini, S.; Petrini, P.; Tanzi, M. C.; Zürcher, S.; Tosatti, S. Poly(Ethylene Glycol) and Hydroxy Functionalized Alkane Phosphate Mixed Self-Assembled Monolayers to Control Nonspecific Adsorption of Proteins on Titanium Oxide Surfaces. Langmuir 2010, 26, 6529-6534.

(55) Zorn, G.; Baio, J. E.; Weidner, T.; Migonney, V.; Castner, D. G. Characterization of Poly(Sodium Styrene Sulfonate) Thin Films Grafted from Functionalized Titanium Surfaces. Langmuir 2011, 27, 13104-13112.

(56) Canepa, P.; Solano, I.; Uttiya, S.; Gemme, G.; Rolandi, R.; Canepa, M.; Cavalleri, O. Phosphonate Molecular Layers on $\mathrm{TiO}_{2}$ Surfaces. MATEC Web Conf. 2017, 98, 8-11.

(57) Boissezon, R.; Muller, J.; Beaugeard, V.; Monge, S.; Robin, J.-J. Organophosphonates as anchoring agents onto metal oxide-based materials: synthesis and applications. RSC Adv. 2014, 4, 3569035707. 
(58) Tsud, N.; Yoshitake, M. Vacuum Vapour Deposition of Phenylphosphonic Acid on Amorphous Alumina. Surf. Sci. 2007, 601, 3060-3066.

(59) Cavalleri, O.; Gonella, G.; Terreni, S.; Vignolo, M.; Floreano, L.; Morgante, A.; Canepa, M.; Rolandi, R. High resolution X-ray photoelectron spectroscopy of L-cysteine self-assembled films. Phys. Chem. Chem. Phys. 2004, 6, 4042-4046.

(60) Uvdal, K.; Bodö, P.; Liedberg, B. L-Cysteine Adsorbed on Gold and Copper: An X-Ray Photoelectron Spectroscopy Study. J. Colloid Interface Sci. 1992, 149, 162-173.

(61) Dodero, G.; De Michieli, L.; Cavalleri, O.; Rolandi, R.; Oliveri, L.; Daccà, A.; Parodi, R. L-Cysteine Chemisorption on Gold: An XPS and STM Study. Colloids Surf., A 2000, 175, 121-128.

(62) Fears, K. P.; Creager, S. E.; Latour, R. A. Determination of the Surface $\mathrm{pK}$ of Carboxylic- and Amine-Terminated Alkanethiols Using Surface Plasmon Resonance Spectroscopy. Langmuir 2008, 24, 837843.

(63) Vega, A.; Thissen, P.; Chabal, Y. J. Environment-Controlled Tethering by Aggregation and Growth of Phosphonic Acid Monolayers on Silicon Oxide. Langmuir 2012, 28, 8046-8051.

(64) Hanson, E. L.; Schwartz, J.; Nickel, B.; Koch, N.; Danisman, M. F. Bonding Self-Assembled, Compact Organophosphonate Monolayers to the Native Oxide Surface of Silicon. J. Am. Chem. Soc. 2003, 125, 16074-16080.

(65) Meroni, D.; Lo Presti, L.; Di Liberto, G.; Ceotto, M.; Acres, R. G.; Prince, K. C.; Bellani, R.; Soliveri, G.; Ardizzone, S. A Close Look at the Structure of the TiO 2 - APTES Interface in Hybrid Nanomaterials and Its Degradation Pathway: An Experimental and Theoretical Study. J. Phys. Chem. C 2017, 121, 430-440.

(66) Graf, N.; Yegen, E.; Gross, T.; Lippitz, A.; Weigel, W.; Krakert, S.; Terfort, A.; Unger, W. E. S. XPS and NEXAFS Studies of Aliphatic and Aromatic Amine Species on Functionalized Surfaces. Surf. Sci. 2009, 603, 2849-2860.

(67) Iravani, E.; Allahyari, S. A.; Shojaei, Z.; Torab-Mostaedi, M. Surface Modification and Spectroscopic Characterization of $\mathrm{TiO}_{2}$ Nanoparticles with 2-Aminoethyl Dihydrogen Phosphate. J. Braz. Chem. Soc. 2015, 26, 1608-1616.

(68) Gawalt, E. S.; Avaltroni, M. J.; Koch, N.; Schwartz, J. SelfAssembly and Bonding of Alkanephosphonic Acids on the Native Oxide Surface of Titanium. Langmuir 2001, 17, 5736-5738.

(69) Hamoudi, H.; Prato, M.; Dablemont, C.; Cavalleri, O.; Canepa, M.; Esaulov, V. A. Self-Assembly of 1,4-Benzenedimethanethiol SelfAssembled Monolayers on Gold. Langmuir 2010, 26, 7242-7247.

(70) Gao, W.; Dickinson, L.; Grozinger, C.; Morin, F. G.; Reven, L. Self-Assembled Monolayers of Alkylphosphonic Acids on Metal Oxides. Langmuir 1996, 12, 6429-6435. 